\title{
Leveraging the sport participation legacy of the London 2012 AQ1 Olympics: senior managers' perceptions
}

Emily Jane Hayday, Athanasios (Sakis) Pappous and Niki Koutrou

School of Sport and Exercise Sciences, University of Kent, Kent, UK

\section{ABSTRACT}

The purpose of this study was to understand how a sports mega event (SME) was leveraged to try and increase participation, through the investigation of national governing bodies (NGBs) opinions and attitudes. Critical realism (CR) was used as a tool to aid understanding of leveraging and legacy conceptualisation, through an empirical investigation. An extensive, mixed method online survey was conducted post London 2012 with senior staff members of NGBs, the main delivery agent chosen to support the participation initiatives associated with the London 2012 Olympics. This research provides valuable findings surrounding the use of $C R$ as a tool to investigate legacy creation, whilst at the same time offering insights to enhance the policy implementation process within the sports development sector. The importance of communication, competitive nature of sports system, media, club engagement, organisational capacity and monitoring and evaluation were highlighted, which provided useful insights into the multidimensional constructs that can aid future leveraging strategies prior to hosting SMEs.

\section{ARTICLE HISTORY}

Received 13 May 2016 Accepted 24 October 2016 KEYWORDS

Leveraging; sporting mega events; sports participation; legacy; Olympic Games

\section{Introduction}

Sports mega events (SMEs) and related outcomes and processes associated with these events such as legacy and leveraging have received much attention within the public and academic domains. There is much deliberation about legacy production and how legacy is defined (Cashman 2003, Cornelissen and Swart 2006, Preuss 2007). Yet, SMEs are expected to deliver outcomes beyond the few weeks of competition; with environmental considerations, legacy planning and long-term sustainability at the core of every host cities bid. Smith (2014a) reinforces the importance of these associated outcomes such as urban regeneration to substantiate the worth of SMEs. There is still much debate about legacy and it has become a focal point of SME academic discourse. Preuss $(2007$, p. 211) notes that 'irrespective of the time of production and space, legacy is all planned and unplanned, positive and negative, tangible and intangible structures created for and by a sport event that remain longer than the event itself'. Weed et al. (2012) reinforce that legacy is a post-event phenomenon and that legacy effects are not only positive. Interestingly, the process of how legacies are created, through initiatives and strategies that are implemented prior and during the SMEs to optimise planned outcomes, known as 'event leveraging' has received limited attention, compared to growing outcome and legacy literature (Chalip 2006). Yet, with SMEs needing to deliver on a 'legacy ethos', which increases the financial burden, legacy is now incorporated into official policy and planning documents (MacAloon 2008, Smith 2014b). Thus, understanding the process of legacy creation through leveraging is critical. 
This paper offers empirical findings to help understand the multiple elements that formulate the creation of the participation legacy and its implementation. It provides different stakeholder perspectives about the elements of legacy that are significant and goes beyond the predetermined,

AQ3 leveraging strategies by utilising a Critical Realist (CR) approach. Building on previous work (Byers, Hayday \& Pappous, under review), this paper aims to develop and illustrate the use of CR within the legacy discourse highlighting the benefits of this multilayered approach.

\section{Literature review}

\subsection{Legacy}

Girginov (2014) suggests that the concept of Olympic legacy was firmly established as central to the Olympic movement in early 2000. Even in its infancy, the symposium recognised the difficulties in defining legacy and provided an inexplicit definition: (IOC 2002, p. 2).

'Olympic legacy ... is multi-disciplinary and dynamic - changing over time - and is affected by a variety of local and global factors. Therefore, whilst being difficult to define, it is a local and global concept, existing within cities, regions and nations, as well as internationally. Moreover, it is fundamental in the understanding of the mission of Olympism in society'.

Legacy can be analysed in many ways and has been described through various typologies such as cultural (Cashman 1998), economic (Gratton et al. 2000, Preuss 2004), health (McCartney et al. 2010), environmental (Chappelet 2008), political (Grix 2013), tourism/destination branding (Hede 2005, Knott et al. 2012) and soft power (Grix and Brannagan 2016), alongside sports participation which will be discussed in a later section. Cashman (2003) emphasised the problematic nature of the term 'legacy' as when used by organising committees it is assumed to be positive and that benefits will filter to local communities automatically. However, Smith (2014b) suggested SMEs are more commonly being justified through the use of other policy initiatives to achieve legacy outcomes as SMEs in isolation do not rationalise their costs.

SMEs and legacy literature has predominantly been outcome focused, through examination of the planned objectives, such as increasing sports participation (Hindson et al. 1994, Mori, 2004, Frawley and Cush 2011, Veal et al. 2012). Delivering a sport participation legacy is challenging, as strategies looking to harness an increase are unlikely to be suitable for individuals who do not engage in sport (Weed 2009, Charlton 2010, Weed et al. 2012, Griffiths and Armour 2013). Yet, minimal research has aided the understanding of legacy and sports development outcomes through empirical data (Frawley and Cush 2011, Veal et al. 2012, Taks et al. 2014, Pappous and Hayday 2015).

\subsection{Leveraging}

In the case of sports participation, for processes and developments to be replicable and sustainable, more knowledge is needed to understand what led to a particular outcome, to ensure the success can be replicated or indeed the failures avoided. Frawley et al. (2013) identified this gap in the sports literature regarding the process, with the dominant focus being on the outcomes rather than on the process. They not only stressed the lack of consideration for 'organisational inputs ... relating to managers of NGBs and their view on hosting international sporting events' (p.106) but also interestingly relating to 'how NGBs aim to capitalise on SMEs and which strategies have been successful or failed' (p. 106). The absence of empirical research was echoed by Bloyce and Smith (2009, p. 8) who suggest that most sports development research is prescriptive, by describing an ideal world, rather than explaining how sports development and policy exist and are delivered through observational, first-hand studies.

Yet, an emerging body of literature is focusing on the planned initiatives and strategies that are implemented prior and during the SMEs, known as event leveraging. This paradigm shift moves 
away from impact and places the focus on the tactical processes aiming to make the most of the desired outcomes. Leveraging restructures event evaluation towards processes to ensure that it is more useful for future event bidding, planning and production (Chalip 2004). Within the relatively emerging field of leveraging, many forms of leveraging strategies have been investigated including social leveraging (Chalip 2006, Kellett et al. 2008), image leveraging (Grix 2012); event business (O'Brien 2006), medium-size and non-mega sporting events (Taks et al. 2014, 2015).

Leveraging can be advantageous, as the positive impact can be valuable to a wider group of individuals (Smith 2014b). Leveraging research is moderately new and to date there is little focus on how and why particular leveraging strategies are effective (Chalip 2014). Preuss (2015) suggests multiple leveraging dimensions, with the most relevant dimensions stating that leveraging is positive and planned. This highlights the restrictive nature when investigating leveraging as it does not allow the possibility to investigate the multifaceted features of legacy creation, which at times are unexpected or negative.

\subsection{English community sport system and NGBs}

The English Community Sport Delivery System shown in Figure 1 is predominantly structured through a club system, in which 'sport organisations are likely to be more autonomous, which will
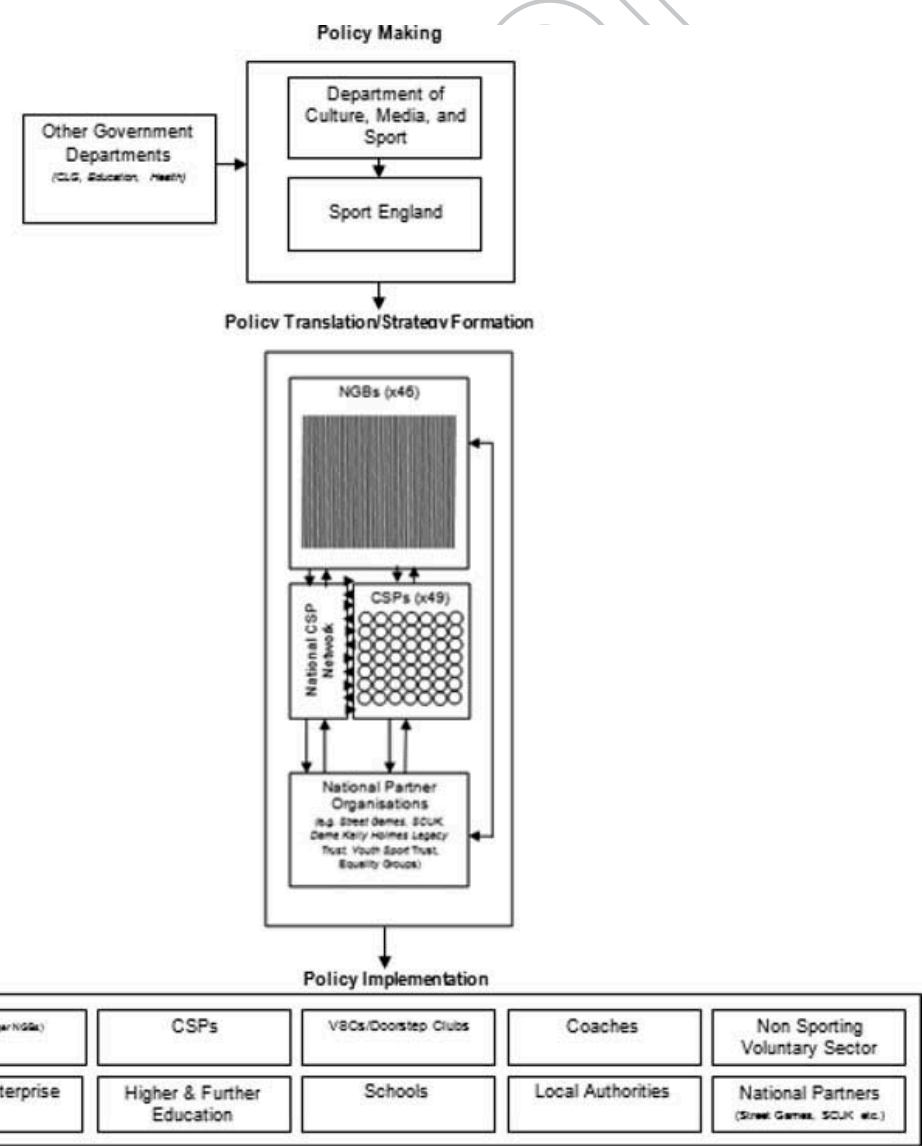

Figure 1. The English community sport delivery system (Harris and Houlihan 2014, p. 115). 
have an impact on the process of policy development and implementation, as well as its efficacy' (Nicholson et al. 2010, p. 4). National governing bodies (NGBs) and their network of voluntary sports clubs (VSCs) are a critical part of the sporting infrastructure in the UK (Taylor, Barrett, \& AQ5 Nichols, 2009). In England, NGBs are heavily reliant on funding from Sport England (SE), a nondepartmental, public body.

To achieve an increase in mass participation, the UK government and in turn SE put mechanisms in place, where eligible NGBs submit whole sport plans (WSPs) every 4 years. This details how they plan to use National Lottery and Exchequer money to increase the number of individuals participating in their sport (Sport England 2016a). Previous research has provided some critical insights on the English VSCs, particularly on issues pertaining to volunteer's attitudes, funding, national policy implementation as well as on communication issues, NGB capacity and competition felt between NGBs and VSCs (Garrett 2004, Nichols and James 2008; Taylor, Barrett, \& Nichols, 2009, Harris et al. 2009, May et al. 2013).

Yet, all of these studies focus on the delivery 'implementation' stage, but few have investigated the 'strategy formation' stage. Research has looked at the board or organisation structure (Theodoraki and Henry 1994, Taylor and O'Sullivan 2009), performance and organisational effectiveness (Papadimitriou and Taylor 2000, Bayle and Robinson 2007), gender issues (Fasting 2000, Shaw and Penney 2003), marketing and social media use (Eagleman 2013) and disability policy implementation (Hums et al. 2003). This research aims to understand how a SME was leveraged to try and increase participation, through the investigation of NGB manager's opinions and attitudes.

\subsection{Policy implementation}

The concept of implementation typically describes the process of putting a proposal or strategy (usually a public policy) into effect, it involves 'exploring causality and the reasons why' (May, Harris \& Collins, 2012, p. 5). The origins of implementation, in regards to the policy process began with the work of Pressman and Wildavsky (1973). They identified that implementation goes further than evaluation 'the mere measurement of outcomes,' by investigating the 'causes' for these outcomes (p. $x v$ ). Within the literature, policy implementation can be divided into three main theoretical perspectives - 'top-down', 'bottom-up' and 'synthesis'.

Top-down theorists such as Pressman and Wildavsky (1973), Bardach (1977), Sabatier and Mazmanian (1980), Hogwood and Gunn (1984) follow a centralised, prescriptive ideal, focusing on policy formation followed by an objective, hierarchical sequence through the system. Bottomup theorists such as Lipsky (1980), Hjern and Porter (1981), Hjern (1982), Hjern and Hull (1982) argue that to truly examine implementation theory, the focus needs to be on the grass-root delivery or street-level bureaucrats' (Lipsky 1980). Then, within the third body of literature, elements of both top-down and bottom-up approaches are combined with 'synthesis' (Elmore 1979, Goggin et al. 1990, Winter 1990, Matland 1995).

Van Meter and Van Horn (1975) extended on Pressman and Wildavsky's (1973) general model to provide a process model for implementation, in which there are six interrelated variables (Figure 2). The model flows left to right, accentuating the focus on hierarchal control, yet, the 'characteristics of implementing agencies' and 'disposition of implementing agents' (Van Meter and Van Horn 1975, p. 482) deviates from the mainstream 'top-down' approach, as it suggests policy change will only be possible, if consensus among actors is high (Pülzl and Treib 2006).This model was predominantly created for the public sector (Skille 2008), yet use of this model has been supported and used by other academics within the sports field (May, Harris \& Collins, 2012; Skille 2008) as it reflects the reality of the top-down community sport policy process (May, Harris \& Collins, 2012).

In an ideal situation, policymakers would like to have absolute control, yet, there are many external variables, leading to a lack of jurisdiction over the end result (Bloyce and Smith 2009). When considering the aims and motives of volunteers and their interpretation of the policy objective, if it does not relate to the agent's intentions, it may be rejected (May, Harris \& Collins, 


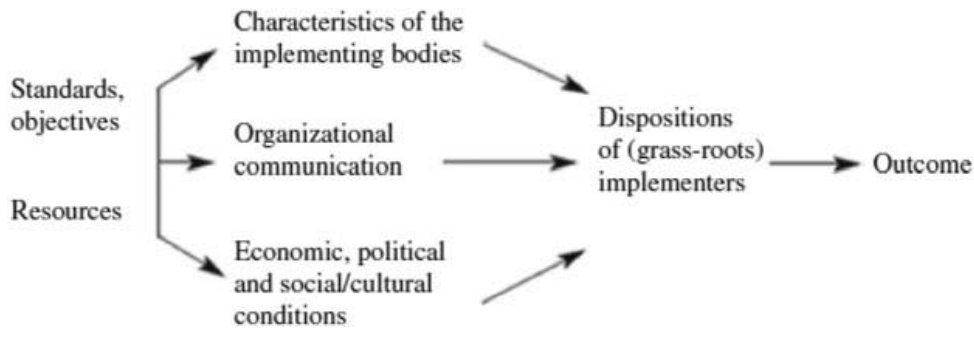

Figure 2. The policy implementation process, Van Meter and Van Horn (1975) modified by Kjellberg and Reitan (1995, p. 143).

2012, Van Meter and Van Horn 1975, Skille 2008). This research allowed investigation into NGBs opinions of this 'top-down' implementation process and gained insight into the perceptions and attitudes of these senior individuals towards hosting SMEs. Taks et al. (2014) study on the sport development outcomes of the Pan-American Junior Athletics Championships highlighted that 'future research should focus on the underlying processes, rather than just the impacts and outcomes' (p.213). This strengthens the relevance and need for this current study into NGB senior management team, who are fundamental actors in the strategy formation phase of the SMEs sports policy.

\subsection{Critical realist perspective on legacy}

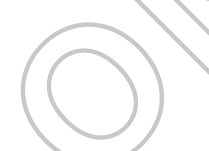

CR sits centrally between positivism and interpretivism, providing a more balanced research perspective (Byers, 2012). Marsh's (1999) six features of CR were used in this research, alongside Tsoukas (1994) notion of multiple levels of reality to outline and explain the use of CR to understand legacy. This study is highly relatable to Byers' (2013) depiction of CR, which was applied to enhance the understanding of volunteer control.

In CR, the social world comprises four modes of reality: material, ideal, artefactual and social and it is this unique aspect of CR that provides the benefit for analysis of legacy creation. 'Material' is not dependent on human activity, it is tangible mechanism (such as a policy), which is often observed, where upon it may be referred to as conceptually mediated (Fleetwood and Ackroyd 2004, Byers 2013). 'Ideal' refers to conceptual, intangible entities such as ideas, beliefs, language and behaviour (Fleetwood and Ackroyd 2004). Artefactual is the buildings, computers as well as 'the interpretation of mechanisms over time ... i.e. this is just the way things are done here' (Byers 2013 , p. 10). 'Social' relates to unplanned social structures and casual powers such as norms, rules, class or gender (Fleetwood 2013). In order to investigate the multifaceted, complex nature of SME legacy creation and the processes involved, CR was used as it provides a valuable tool to investigate the different layers of legacy creation.

Marsh's (1999) six key assumptions, illustrate that there is a reality external to individuals (assumption 1) and this contains deep and superficial structures that are not directly observable (assumption 2). Objects and structures have casual powers, which suggest a need to highlight connecting features of those phenomena (assumption 3). Yet, the actor's extensive knowledge of the 'reality' has a construction effect on the impacts possible from social interrelations (assumption 4). Structures such as cultures, beliefs and ideologies, constrain and enable everyday social activities, rather than determine outcomes (assumption 5). The study of social science involves the study of reflexive agents who can construct, deconstruct and reconstruct structures (assumption 6) to understand, the deep, subtle structures (Byers 2013).

The importance of using CR to investigate legacy creation links to those underlying deep-routed structures that lead to the acceptance or rejection of formal policy and engagement from actors. This relates to individual's values, culture, ownership or identification with the SMEs and highlights 
the multifaceted nature of $\mathrm{CR}$, which requires the analysis of multiple layers of reality to understand legacy production. The critical realist perspective views structures and agents, as elements that in conjunction determine the outcomes of social phenomena (Byers 2013). Structures are the 'relatively enduring institutionalized relationships between social positions and practices located at different levels of analysis that constrain actor's capacities to 'make a difference' (Reed 1997, p. 25). Underlining that, both structures and agents are causal forces, by both initiating and also constraining such action, through agents' production and reproduction of structures (Grix 2010). Yet, 'agents are not without power to resist pressures from the structures they created' (Byers 2013, p. 11). Thus, when investigating the process through which mechanisms were created and/or implemented by NGBs, using CR allows multiple realities to be investigated as legacy cannot be understood by just investigating the structures alone, the influential agents also need to be taken into account to fully understand and learn from this SME.

\section{Method}

This exploratory study utilised a mixed method, case-study approach, guided by a critical realist paradigm in which Marsh's (1999) six assumptions of CR and Tsoukas (1994) view of the multiple levels of reality allowed the concept of legacy creation to be understood, as used by Byers' (2013). Case studies are best suited for investigating contemporary phenomenon and they complement the realist perspective and the acknowledgement of multiple levels of reality (Yin 2013).

\subsection{Development of survey}

In order to develop the survey which was aimed at senior NGB employees, a three-stage approach was followed. A: preliminary question creation, B: exploratory focus groups based on literature review and C: pilot study. First (A), existing literature was analysed within the field of SMEs, community sport, leveraging and policy implementation (Chalip 2006, Skille 2008, Veal et al. 2012, Byers 2013, Harris and Houlihan 2014, May, Harris \& Collins, 2012). This allowed relevant themes to be identified, relating to the importance of investigating strategy creation and the interrelation and impact that the VSC have on the delivery process. This intertwined with the identification and use of Van Meter and Van Horn (1975) implementation model (Figure 2) allowed the survey questions to be created.

The second phase (B), four exploratory focus groups were undertaken with individuals involved in the community sports sector (three NGBs and one CSP). This process was necessary due to the limited existing literature, which investigated the perceptions of NGB senior staff, in relation to hosting SMEs. This led to the identification of additional themes such as knowledge transfer as the competitive nature of the sports system was suggested to have led to a lack of collaboration between sports. Furthermore, relating to Van Meter and Van Horn (1975) 'economic, political and social/cultural conditions' variable, the focus groups highlighted the importance of SE and the method of performance evaluation through the Active People Survey ${ }^{1}$ (APS) within the English context. Additionally, supplementary demographic questions were asked to participants to gain an insight in participant's personal characteristics, motives and beliefs for the 'social' layer of reality within CR. The formulation of these three methods led to the creation of the survey template. This was reviewed by six sports sector and academic professionals, allowing existing content to be adapted or removed, avoiding any issues with clarity and content, prior to data collection.

In the third stage (C), piloting was vital to account for questionnaire wording, sequence of 230 questions, time to complete, administration issues and practicing data collection (Gratton and Jones 2004). The finalised online survey was tested by three individuals, comprising sports management academics and sports development professionals. The pilot was carried out on BOS, through the same system that the participants in the main study used. This ensured that the pilot was undertaken in conditions, as close to the main study, as possible (Gratton and Jones 2004). 


\subsubsection{Participant information}

The online survey was distributed to CEOs, senior and regional managers of the 46 SE-funded NGBs. During the four exploratory focus groups, time restraints were highlighted as a major limitation for NGB head office staff, meaning that distributing the online survey via email was the most suitable method for this participant group. CEOs and the management team were a suitable target group due to their involvement within SEs participation legacy plans. Both NGBs and VSCs were fundamental in the delivery of this strategic objective (Sport England, 2008). With regards to sampling, originally only CEO's and senior managers were going to form the participant group. Yet, initial findings highlighted the importance and detailed knowledge held by the regional managers, who work in a much closer capacity with the VSCs. Thus, the decision was taken to include these individuals within the data set.

\subsubsection{Protocol}

Data were collected between February and June 2015, individuals would have been in post for 3+ years, to account for pre/during London 2012 Games involvement. A personalised email was sent to each individual identified as a possible survey respondent, all of which were available in the public domain via the NGB websites. A Participant Information Sheet (PIS) was attached to ensure participants were clear on the context of the study. Data were collected through an exploratory online survey and included a mixture of quantitative and qualitative questions. Quantitative responses were analysed using descriptive statistics and qualitative results were analysed using Open and Axial coding (Corbin and Strauss 1990, Bryman 2008). Each of the 28 variables in the survey was measured on a 7-point Likert scale, ranging from strongly disagree to strongly agree. These questions were created to reflect the lack of current considerations for this area identified in the literature, as minimal research had investigated the perceptions of NGBs managers towards hosting SMEs (Frawley et al. 2013). Medium and interquartile ranges (IQR) are presented due to the individual Likert items being treated as ordinal variables.

\section{Results}

105 responses were received for this study, allowing the researchers to gain an insight into the opinions and attitudes of the senior and regional managers involved in 37 out of $46^{2}$ SE-funded sports, resulting in an $83 \%$ response rate across the sports targeted.

Employment type was split into CEOs, $13.3 \%$, national managers, $52.4 \%$ and regional development managers, $28.6 \%$, whilst $5.7 \%$ did not state their position. The duration in post provided an indication to the level of staff involvement with the leveraging strategies. The data reinforce the variation and turnover of staff within the sector, as $37 \%$ of respondents have been in post for $4+$ years, whilst $61 \%$ of individuals had only being in post for between 0 and 3 years, ( $2 \%$ missing data points). Yet, $36 \%$ of these respondents did work for the NGB in a junior position, prior to their current $\mathrm{CEO}$, senior or regional manager role, possibly suggesting they may have been involved with the leveraging strategies and programmes in a junior capacity. Other demographic analysis highlighted respondents gender was predominantly male, $69 \%$ compared with $31 \%$ female.

\subsection{Quantitative data}

The variables outlined in Table 1 were used to measure the attitudes and opinions of the respondents towards the 2012 Games.

The variable that achieved the strongest agreement related to the attitudes of participants and their satisfaction and support for the hosting of the 2012 Games. This is important to note, as individuals were pleased that London was hosting the 2012 Games ( $M d n=7, I Q R=7,7$ ) and they were in full support of the event ( $M d n=7, I Q R=7,7$ ). The IQR highlights the consistency within the results $(7,7)$ and this reflects the positive attitudes felt by these managers that were 
Table 1. Descriptive analysis: medium and IQR

\begin{tabular}{|c|c|c|}
\hline Variable & Median (Md) & $\mathrm{IQR}^{4}$ \\
\hline $\begin{array}{l}\text { We received advice and liaised with other NGBs to decide on what programmes and strategies to } \\
\text { implement in order to increase participation }\end{array}$ & 4 & 3,5 \\
\hline I was pleased with the financial support provided by Sport England in the build-up to the Games & 4 & 4,6 \\
\hline The clubs were fully aware and understood our participation strategies and programmes & 5 & 4,6 \\
\hline $\begin{array}{l}\text { I understood the requirements placed on us by Sport England in our responsibility to increase grass- } \\
\text { root participation }\end{array}$ & 6 & 6,7 \\
\hline I was pleased with the financial support provided by Sport England after the Games & 5 & 4,6 \\
\hline The specific monitoring by Sport England has made our organi & 5 & 3,6 \\
\hline I felt satisfied with the funding opportunities that hosting the & 5 & 4,6 \\
\hline $\begin{array}{l}\text { Our organisation implemented specific participation programmes/strategies to make the most of the } \\
\text { Games }\end{array}$ & 5 & 4,6 \\
\hline I feel the Games provided us with a unique opportunity to showcase our sport & 7 & 6,7 \\
\hline I felt satisfied with the level of guidance provided by Sport & 4 & 4,5 \\
\hline $\begin{array}{l}\text { Voluntary clubs had the necessary financial resources to successfully implement our programme } \\
\text { meet participation objectives }\end{array}$ & 4 & 2,5 \\
\hline Implementation of our participation programmes was consistent across our club network & 4 & 3,5 \\
\hline $\begin{array}{l}\text { I am satisfied with the APS (or your alternative) as an evaluative method from v } \\
\text { decided }\end{array}$ & & 2,5 \\
\hline I felt satisfied with the level of guidance provided by Sport England after the G & 4 & 4,6 \\
\hline We fully engaged clubs with the programmes that were & 4 & 4,6 \\
\hline $\begin{array}{l}\text { Voluntary clubs had the necessary guidance to successfully implement our programmes and meet } \\
\text { participation objectives }\end{array}$ & 4 & 3,5 \\
\hline $\begin{array}{l}\text { The APS monitoring and evidence needed by Sport England have improved our research and insight } \\
\text { into our participation programmes and client demographics }\end{array}$ & 4 & 3,6 \\
\hline $\begin{array}{l}\text { Knowledge transfer from the NGB to the clubs regarding the successes and failures of our participation } \\
\text { programmes occurred }\end{array}$ & 4 & 4,5 \\
\hline $\begin{array}{l}\text { The nation's expectations surrounding the Olympic objective of increasing participation, provided an } \\
\text { opportunity for us to inspire people to take up the sport }\end{array}$ & 6 & 6,7 \\
\hline If we were to host the Games again, I would not change our community sports strategy and approach ${ }^{5}$ & 5 & 4,6 \\
\hline $\begin{array}{l}\text { We created and planned participation strategies and programmes to ensure we could capitalise on the } \\
\text { Games }\end{array}$ & 5 & 4,6 \\
\hline $\begin{array}{l}\text { We were happy to share our successes with other NGBs, ev } \\
\text { within the English sports system }\end{array}$ & 6 & 4,6 \\
\hline I was pleased that we were hosting the 2012 Olympic Games & 7 & 7,7 \\
\hline $\begin{array}{l}\text { I feel that the Whole Sport Plan, 4-year funding cycles have been beneficial to help us focus and set } \\
\text { development targets for our sport }\end{array}$ & 6 & 5,6 \\
\hline I feel we achieved the grass-root participation outcomes that we set out to achieve & 5 & 4,6 \\
\hline The communication between our NGB and the voluntary club network requires no improvements & 5 & 4,6 \\
\hline $\begin{array}{l}\text { The plan to host the London } 2012 \text { Games was taken without considering the capability and ability for } \\
\text { us (NGBs) to support the participation objective* }\end{array}$ & 4 & 3,6 \\
\hline I was in full support of the London 2012 Olympic Games & 7 & 7,7 \\
\hline
\end{tabular}

instrumental in the planning and delivery of the London 2012 Games and its associated leveraging strategies. This question depicts the 'Ideal' layer of reality within CR and highlights the interpretative perspective of key stakeholders and their positive beliefs towards SMEs.

Most respondents felt that the Games provided them with a unique opportunity to showcase their sport ( $M d n=7, I Q R=6,7$ ), with $82 \%$ of respondents selecting between slightly strongly agree (range 5-7). Respondents who highlighted either neutral or disagreement value (18\%) all worked for a non-Olympic sport. This reinforces the limited opportunities that non-Olympic sport employees felt they had, to capitalise on the SMEs.

Interestingly, the public expectations surrounding London 2012 and the outlined legacy promise, which aimed to increase participation was highlighted by the respondents as an opportunity to inspire people to take up their sport ( $M d n=6, I Q R=6,7)$. Similarly, the results showing disagreement $(7 \%)$ were made by employees working for a non-Olympic NGB. The standards and objectives of how the leveraging strategies would be achieved by hosting SMEs were outlined by SE for NGBs. This highlighted the central role that NGBs played in this legacy production and most respondents felt they understood the requirements that were placed on them by $\mathrm{SE}(\mathrm{Mdn}=6$, 
$\mathrm{IQR}=6,7)$. This is reflected by $82 \%$ of the participants being in agreement, whilst $16 \%$ of the sample held a neutral opinion and $2 \%$ were in disagreement. Within the sample, $15 \%$ of the participants were not in post during or pre the London 2012 Games, meaning they may have had limited knowledge of the requirements that were set by SE.

Employees expressed slight agreement on the ability of NGBs to capitalise on the 2012 Games to increase grass-root participation, through the planning and creation of specific programmes $(\mathrm{Mdn}=5, \mathrm{IQR}=4,6)$. Furthermore, implementation of these specific participation programmes and strategies was met with similar agreement $(M d n=5, I Q R=4,6)$. This could suggest that even though all NGBs had to submit WSPs and were seen as core to Sports England's policy objectives to increase participation, only slight agreement was felt regarding the benefits of these participation programmes. Detachment and neutral viewpoints were shown by NGB senior staff, as when respondents were asked whether the plan to host the Games considered the capacity and ability of NGBs to support the participation objective both non-participating ( $\mathrm{Mdn}=4, \mathrm{IQR}=4,5)$ and participating NGBs (Mdn $=4, \mathrm{IQR}=2,5)$ highlighted an impartial viewpoint. These results suggest that no respondents agreed that the ability and capacity of their organisations was considered during legacy planning. This links to the 'Artefactual" layer of reality, as respondents were able to highlight the disadvantage they felt through this lack of national-level organisational planning.

The main resource mentioned throughout this research and within the literature is the funding and financial support for grass-root sport delivery. No strong feelings were shown by the respondents with regards to the funding opportunities that hosting the 2012 Games brought their sport $(M d n=5, I Q R=4,6)$. For the majority of the questions, resources were split into two main groups, 'financial' resources and 'guidance'. These components were looked at both pre and post the 2012 Games. It is worth noting that not all respondents were in post pre London 2012. Thus, many individuals may have selected the 'neutral' scale point (scale value 4) as they might have not been aware of the resources that were available pre Olympics. This is problematic, due to the challenging nature of creating a long-term sustainable legacy, if there is a high turnover of employees, alongside the ephemeral engagement with a sport event.

Similar results were seen regarding the resources provided to NGBs by $\mathrm{SE}$, both pre and post the SMEs. Satisfaction with financial support provided by SE highlighted a neutral viewpoint pre Games $(M d n=4, I Q R=4,6)$ with slight agreement illustrated post Games ( $M d n=5, I Q R=4,6)$. This may suggest that minor improvements were felt by the NGB staff when thinking about financial support provided by SE.

With regards to respondents' satisfaction with the guidance achieved pre Games ( $\mathrm{Mdn}=4$, $\mathrm{IQR}=4,5$ ) to post Games ( $M d n=4, I Q R=4,6)$, no change was noted. Yet, the results highlight neutral feelings by the respondents. As stated earlier, this could relate to the duration in post and subsequently the insufficient knowledge some participants may have had. Respondents were also asked whether they felt NGBs provided the delivery agencies (VSCs) with sufficient resources to implement the leveraging initiatives, a neutral viewpoint was shown for both financial resources $(\mathrm{Mdn}=4, \mathrm{QQR}=2,5)$ and guidance $(\mathrm{Mdn}=4, \mathrm{QR}=3,5)$. These data do not provide a clear understanding on whether any issues were felt with the legacy production process.

An overarching component that is evident and plays a role in all themes mentioned above is communication. Organisational communication is vital to ensure clubs are fully aware of the objectives and strategies that the NGB is looking to implement through the top-down policy delivery system that exists within England. The respondents somewhat agreed that communication improvements were needed between the $N G B$ and club network ( $M d n=5, I Q R=4,6$ ). Knowledge transfer is vital to ensure sharing of good and bad practice as it allows replication of the positive and provides advice to avoid the unsuccessful strategies and processes. Looking at the pattern of knowledge transfer between NGBs, pre and post the 2012 Games, there is a clear difference of attitude. Pre London 2012, respondents were asked if they received, liaised or obtained advice from other NGBs to decide on what strategies to implement in order increase participation; this was met with a neutral viewpoint $(M d n=4, I Q R=3,5)$. Yet, after the SME respondents highlighted 
agreement $(\mathrm{Mdn}=6, \mathrm{IQR}=4,6)$ when asked whether they shared their successes on increasing grass-root participation with other NGBs. This may suggest that post the 2012 Games, respondents were more willing to communicate with other sports to build on the successes gained during the SME and this is indicative of the competitive nature of funding allocation in England. Additionally, knowledge transfer within the organisation, from the NGB to the VSC was met with a neutral viewpoint (Mdn $=4, \mathrm{IQR}=4,5)$.

Monitoring and evaluation took the form of the APS results and the WSPs that were produced by each NGB. Respondents' satisfaction levels with the APS as an evaluative method, through which their funding is partly decided was negative ( $M d n=3, I Q R=2,5$ ). Interestingly, when looking at the individual positions that respondents held within their NGB, the disagreement was heightened the further away from the policy creation and the closer to implementation the employees were. CEOs held a neutral view $(\mathrm{Mdn}=4.50$, IQR $=3,6)$, whilst the national managers $(\mathrm{Mdn}=3, \mathrm{IQR}=2,5)$ and regional managers $(\mathrm{Mdn}=3, \mathrm{IQR}=2,4)$ held a level of disagreement. These results could suggest that individuals further away from the CEO and the core funding decisions may have reduced knowledge and acceptance of this method of evaluation.

There were positive impacts mentioned with regards to the monitoring and evaluation and the benefits that the WSP provided them as an organisation to focus and set development targets for their sport (Mdn $=6, \mathrm{IQR}=5,6$ ). Non-Olympic sports highlighted how the specific monitoring through methods such as the APS, by SE have made their organisation more efficient ( $M d n=5.50$, $\mathrm{IQR}=4,6)$. Yet, representatives of Olympic sports demonstrated no strong feelings ( $\mathrm{Mdn}=4$ $\mathrm{IQR}=3,5$ ). This stresses the encouraging impact that a large-scale survey and strong monitoring by the funding organisation (SE) can have in terms of improving the governance and processes within sports organisations. This could act as a catalyst to strengthen organisational processes for future SMEs leveraging and policy implementation.

When the senior managers of Olympic NGBs were asked to reflect on whether progress has been made on their participation outcomes post London 2012, the majority were in agreement $(\mathrm{Mdn}=6, \mathrm{IQR}=4,7)$. Yet, NGBs that participated in the Games held a slightly lower agreement level $(\mathrm{Mdn}=5, \mathrm{IQR}=4,6)$. NGB respondents identified that for them to effectively produce and sustain a legacy and the process of policy implementation itself, many changes need to be made. These changes relate to improvements in planning and club preparation surrounding SMEs, increasing the use and role of media, enhancing local participation programmes, alongside other points raised earlier such as the need for more resources and the importance of research and insight.

\section{Discussion}

This discussion focuses on the rich qualitative part of the survey, which allowed respondents to highlight their views and opinions in relation to key themes as well as the quantitative sections of the survey.

\subsection{VSC commitment and implementation}

The community sports system is a network of organisations, VSCs and individuals that all need to understand what is required of them. Previous research has investigated the challenges with interorganisation engagement (NGB to VSCs) and communication (Cuskelly et al. 2006; Harris et al. 2009; May, Harris \& Collins, 2012). Yet, this has not been researched to date, from a SMEs perspective looking into the associated policy aimed, but rather general sports policy.

Yet, even though a large percentage of the NGB staff stated they understood the sport policy objectives, to achieve the Olympic legacy by increasing participation. Van Meter and Van Horn (1975) state that effective policy implementation is more achievable when there is agreement between policymakers and implementers of that objective. Yet, as highlighted in previous work 
by May, Harris and Collins (2012) and within this study, a disconnection was felt between the knowledge and acceptance of policy across these two groups (NGBs and VSCs). Club engagement issues were met with strong feelings by NGB staff, relating to the attitude of the grassroot implementers (club coaches and volunteers). Many respondents highlighted that VSCs have a negative attitude and this was a key cause for the lack of club engagement with the NGB leveraging policies and strategies. 'Not all clubs wanted to engage' (Respondent 20 - national manager) and 'clubs had a distrust of the NGB, personalities often come into play in a voluntary run organisation' (Respondent 91 - regional manager). This relates to the 'ideal' layer of CR, as the club coaches' views and beliefs have shaped the way they perceive and engage with the NGB in order to produce legacy. Alongside this, two practical issues were identified by the respondents. First, not all clubs are part of the NGB strategy and its implementation network, as it can 'depend on the county targets' whether clubs are engaged (Respondent 31 - regional manager). This 'material' observable factor, which formulates part of the tangible legacy strategy is itself limiting legacy creation. Furthermore, this lack of engagement with all VSCs can be a byproduct of other 'material' factors, such as, limited club capacity or funding that is discussed in a latter section.

One respondent recognised that the strategy does not align to coaches'aims for the club. As:

'Participation increases within 14-25 [age category] does not meet the interest or needs of all of our clubs. Many clubs wish and feel it is necessary to focus on participation at the 9-14 age bracket in order to then retain participants at $16+^{\prime}$ (Respondent 43 - national manager).

This echoes the findings in Harris et al. (2009) research into top-down policy approach as there is a lack of consensus and involvement felt for the policy itself. This reinforces the importance of communication in VSCs feeling more supported and engaged. Second, it was also suggested that some coaches may need to be upskilled as one regional manager highlights their 'clubs are run typically by working class people builders etc. I think a lot of them didn't understand certain terms and what is being asked of them' (Respondent 28 - regional manager). Within the CR perspective understanding the 'social' characteristics, experience and values of these stakeholders is necessary as these underlying mechanisms shape their perceptions as well as their ability to enhance or inhibit legacy production.

One participant felt that within their club structure, not all coaches held the appropriate qualification. As clubs 'don't all have level 2 coaches and as most of our programmes dictate a level 2 must be involved in delivery, then some clubs will never be able to support our programme delivery' (Respondent 23 - regional manager). By investigating the 'social' context through $\mathrm{CR}$, some of these issues could be improved by upskilling volunteers and for future policy implementation strategies it would be beneficial to create a targeted strategy focused on VSCs capabilities and characteristics to ensure the club network could be used to its full 430 capacity.

Similarly, to club engagement issues, coaches' negative views linking to their needs and beliefs (social and ideal layer of CR) were noted. For example, 'many clubs are very set in their ways regarding how they operate and therefore do not appreciate change or take the time to understand the reasoning for change' (Respondent 27 - regional manager). This links into the stakeholders 'Ideal' interpretive perspective of legacies existence, how they are involved in the legacy objective, this caused difficulties for policy creators with implementation of NGB strategies and programmes at the VSC level. NGB staff were able to engage with clubs, yet, the 'disposition of the grass root implementers' was not aligned with the views of the policymakers and strategy formation organisations. Yet, this 'top-down' policy implementation process, in which the VSCs have limited involvement in the legacy production leads to negative perspectives. It is this interpretation of these implementation mechanisms, that leads to clubs feeling disempowered when creating legacy (artefactual layer of CR). This is an identified issue within the field of sports policy and reinforces the difficulties of such a diverse sector (May, Harris \& Collins, 2012). 


\subsection{Disengagement of non-Olympic sports}

Many respondents that worked for a non-Olympic sport were disinterested in the 2012 Games, as they felt it was 'not overly relevant to us not being an Olympic Sport in 2012' (Respondent 39 national manager). Others echoed this as '[our sport] isn't an Olympic sport ... difficult to take advantage' (Respondent 60 - regional manager). This highlights the difficultly for non-Olympic sports to feel part of the leveraging strategy and to capitalise on the SMEs. By using CR as a guiding perspective, the analysis of the 'artefactual' views of stakeholders was possible. This provided context as to why stakeholders feel disadvantaged and possibly negative towards SMEs due to their lack of engagement as non-Olympic sports.

This issue was further stressed by the CEO of a non-Olympic sport who stated:

'I represent a non-Olympic sport and therefore we were not included in the central planning for the legacy programme. We were consulted with as to how we could assist in our priority areas with the Olympic legacy programme but this was done at a local level and not national co-ordinated apart from internally by us. We held informal conversations with other NGB's but we were not involved in co-ordinated conversations' (Respondent 76).

This illustrates a possible limitation within the 'material' layer of CR as more centralised involvement is needed from the policymaking organisations (SE and DCMS) to engage with policy translation and strategy creation bodies, such as the NGBs of both Olympic and non-Olympic sports. This strategy to utilise sports, both included and not included in London 2012 in the legacy production resulted in a negative opinion held by non-participating sports, who felt a lack of involvement and isolation. They stressed legacy creation was done locally and 'internally by us' and 'as our sport was cut from the Olympics for 2012, so some clubs were not interested in anything Olympic' (Respondent 3 - regional manager). Analysis of the 'artefactual' layer illustrates the disadvantage felt by the stakeholders towards legacy creation due to the lack of effort made to engage non-competing sports.

\subsection{Resources}

Qualitative data highlighted some of the issues with the guidance process, which may aid understanding for the possible reasons a neutral value was given. First, within the 'material' layer of $C R$, the superficial, tangible evidence of legacy production. It was not possible to engage with all clubs for practical reasons as capacity of the NGB itself is a limitation. As there is a lack of funding - we could not cover all clubs - we were working with a shoestring budget and had to work where local authorities provided local funding' (Respondent 99 - regional manager). The CEO of one Olympic sport suggests due to 'the resources of a small NGB ... [we] tend to gravitate towards easy wins' (Respondent 87). Yet, results suggested that when and where NGBs were able to put in the resources, engagement and acceptance by the club was evident. One respondent captured the concern stating that:

'Individuals motivations and what they want, some are extremely interested and others are not bothered. Also resources- it is impossible for us to assist and help every club in the region so there is a tiering system and you visit clubs based on need, so some clubs may get missed or not feel supported- it is tough' (Respondent 28 - regional manager).

Yet, the 'easy wins' were critical for NGBs, meaning for smaller, less developed clubs their level of isolation from the NGBs increased, which negatively affects stakeholder's views through the 'artefactual' lens of $C R$ as their level of trust in the development of legacy through the NGBs decreases. This caused a negative cycle of processes between the NGB and VSC that is hard to amend due to the current target-driven system. As one national manager states:

I've no doubt that Clubs with Clubmark $^{3}$ status received most attention from full time staff, doubtless due to time constraints and a need to concentrate on clubs which had the most "going 
for them" to obtain the best results. Therefore, smaller/less organised clubs would receive much less time and support' (Respondent 103).

Furthermore, it was the characteristics of the club itself that limited or ensured the engagement and implementation of specific strategies. 'Clubs are run by volunteers of varying quality and with varied amounts of time available. Those clubs with the best leadership got really engaged with implementation' (Respondent 80 - national manager). The 'capacity at some clubs' limits the possibility to implement (Respondent $60-$ CEO), as 'again because of the reliance on volunteers - sports clubs themselves have limitations on just how much they can increase participation' (Respondent 65 - national manager).

This highlights a future recommendation for NGBs to develop a better understanding of the club network and each VSC characteristics by analysing the 'social' layer of the CR perspective to gain a more detailed understanding of individuals, beliefs, class, cultural values and experiences. Improving the relationships between the NGB and club was referred to heavily when participants were asked about communication and the issues with implementation of the legacy policy. One respondent echoed the views of many, stating that:

'[We have to ensure] effective communication between NGB's, clubs, commercial delivery partners and volunteers. Pre-empt demand for sporting activity and ensure you are able to implement projects that can cope with demand prior to the Olympics not just reactively' (Respondent 27 - national manager).

\subsection{Communication}

With regards to communication, some participants felt their communication as an organisation was effective, which leads to a clear understanding by the VSCs of the NGBs strategy. It 'was explicit and was achievable by all parties' (Respondent 6 - national manager). Others illustrated how they are overcoming this issue and highlighted their detailed support and communication lines via a regional system:

'We worked with our county associations to write delivery plans linked to our Whole Sport Plan, putting responsibility in their hands. We helped them come in line with [our sports] governance guidelines ensuring they are fair/quality/transparent' (Respondent 25 - regional manager).

Yet, one of the key issues limiting the effective improvement of communication for some NGBs nationally is the limited resources available (staff, time and finances). This led to difficulties with policy implementation and legacy creation within the diverse sports system as there are vastly different amounts of resources and income at their disposal of certain NGBs. One respondent states:

'We have moved a long way in the past few years.... However, as a smaller NGB without regional staff the links we make are limited and time consuming. We are seen as Big Brother dictating what should happen, and too few clubs respond unless they want funding' (Respondent 49 - national manager).

The abilities of the workforce are also limited within larger NGBs. As the CEO of one sports states 'We have 850 clubs; through [a] programme we have developed good engagement with about 250 clubs' (Respondent 83 ). As 'even with a large full time support staff there will always be issues of communications between HQ [Head Quarters] and a membership of 100K plus' (Respondent 103 national manager).

\subsection{Knowledge transfer between NGBs}

The qualitative elements provided an insight into the reasons why knowledge transfer between NGBs did or did not occur. Some (4\%) individuals stated that knowledge transfer and collaboration should and has occurred formally through NGB forums organised through SE. 'There is no reason why best practice (or common sense) is not shared. SE encourages this through, 'Sports Hall 
groups, playing field groups etc.' (Respondent 63 - national manager). One participant highlights the competitive nature of the funding system as a limiting factor, which will be discussed in detail later. Yet, they also acknowledge the benefit that collaboration could have if supported by $\mathrm{SE}$, 'knowledge sharing between NGBs needs to be led and facilitated by Sport England. NGB's have little/no incentive to share success with other NGBs due to the competitive nature of funding (Respondent 77 -national manager). This indicates a limiting factor with regards to the tangible 'material' component of legacy production as the current funding for legacy is discouraging the sharing of best practice.

Whereas, others indicated that it occurs on an informal basis through friends and known colleagues within other NGBs, especially within smaller NGBs. 'Being a smaller NGB we are always consulting with other NGB's about their programmes to form our own, it is generally quite an open process' (Respondent 33 - regional manager). This was resonated by another regional manager who stated 'as a relatively small sport we try hard to be active with SE and other NGBs, in order to ensure we are celebrating our successes' (Respondent 44).

Yet, the majority reinforced the view illustrated in the quantitative data that knowledge transfer between NGBs did not occur prior to the SMEs due to 'the nature of funding ... [which] makes it exceptionally difficult to encourage collaboration between NGBs' (Respondent 26 - regional manager). One participant suggests that 'Sport England needs to significantly change the way it distributes investment to encourage collaboration at an early stage of each planning cycle (Respondent 62 - national manager), as currently, within the sports system NGBs 'are competitors for new participants' (Respondent 49 - national manager). Yet, Respondent 49 also suggested that 'with careful planning further work for collaboration can and should work'. This reinforces the underlying issues with the competitive funding system itself, which resulted in isolated working between organisations within the same sports network, that interestingly are trying to achieve the legacy objective of increasing national participation rates.

\subsection{Knowledge transfer within NGBS}

Corresponding to the competitive theme noted between NGBs themselves, this is also happening at a VSC level. This lack of collaborative working within a single sport can cause issues for the sports holistic development and participation rates. Especially, for NGBs with limited resources means that they are unable to assist all VSCs. Yet, this is a by-product 'towards easy wins' (Respondent 87 - CEO), as highlighted by NGB staff, resulting in some clubs being left without any support, which affects legacy production through the 'Material' layer of CR. Thus, the VSCs, due to the funding system, need to be the most successful club within the area, as this ensures they receive the support and can sustain their club financially. One individual stated: 'Clubs are in "competition" with each other to be the best and biggest. It is hard to get members to see the wider picture of why sharing practice is a good thing and can help others and whilst still being a leading club in that area' (Respondent 32 - national manager). In addition, 'clubs are territorial and insular and do not like to share best practice or general information. They are worried they will lose members in doing so' (Respondent 37 - regional manager). This highlights a possible need for NGBs to adapt the guidance and funding mechanisms or create culture between VSCs, where they see each other as partners rather than competitors. By developing the current processes within the 'material' layer of $\mathrm{CR}$, this may enhance legacy production.

\subsection{Monitoring and evaluation}

No positive views towards the APS were given by any respondents and reasons for this were highlighted within the qualitative results. Individuals felt unhappy with these methods by which the APS is conducted through primarily landline phone call and the sample sizes. The CEO of one NGB states I am 'not sure it has [had a positive impact]' (Respondent 89 - national manager). This 
was echoed by another respondent who suggests 'I am not confident this method of gaining information gives a true picture of our sport, so I do not think it has had a positive impact' (Respondent 24 - CEO). Respondent 66 states, 'the demographic [does] not cover all the aspects of our sport, as it relates purely to activity and not to all the other aspects involved in our sport that also require physical activity' (national manager).

Furthermore, the pressure of specific 'material' strategies to work with specific age groups 14/16 + and the focus towards short-term targets was noted as a concern. 'As a participation team, we are reactive to APS (rather than proactive) and as a result have just had funding cut. It's a shortsighted cycle to become part of' (Respondent 52 - regional manager). This was reinforced by the CEO of one NGB who suggests:

'It can be a distraction, chasing APS targets is not always the right approach for an NGB that needs to be building sustainable growth, not short-term quick wins to meet targets. But it has challenged us to think about certain aspects of the sport in a new way' (Respondent 45).

The participation criteria focusing around the 14/16+ age range caused problems for some NGBs, as 'there is too much of a focus on 14+ participation in the sport' (Respondent 25 - regional manager). The 'pressure to work with $14 / 16+$ age group ... perhaps is not the best for our sport' (Respondent 18 - regional manager). The positive influence that the APS can have on the development of their NGBs and their individual insight and research teams was also recognised. Four main themes arose when respondents were asked about the beneficial aspects of the APS. First, unsurprisingly due to the attitudes discovered above, some individuals (23\%) felt that there was no positive impact or it was unclear what any positives were. This could link to their position within the NGB, being closer to the policy implementation process or the length of time they held their position. Few respondents (4\%) noted the identifiable positives that the APS results provided them with an increase in funding as:

'It has raised the profile of our sport as our APS figures are compared against other sports. Our participation is perhaps higher than previously thought by SE and our figures have been increasing over the cycle which encourages SE to look more favourably at supporting our sport' (Respondent 11 - CEO).

Yet, as noted in the quantitative results, respondents felt the APS, made their organisation more efficient ( $M d n=5.50, I Q R=4,6$ ) and they highlighted the benefits that the WSP provided them as an organisation to focus and set development targets for their sport ( $M d n=6, I Q R=5,6$ ). These illustrate the governance improvements made through this evaluation method (APS) and suggest a 'material' construct of legacy production that could be used by future SMEs hosts to provide efficiency and target setting within NGBs, through the use of a performance linked national survey. NGBs are strengthening their own insight into their customers and collating evidence to illustrate to SE their achievements in relation to the legacy and policy objective. Additionally, the majority of respondents $(40 \%)$ identified the positives of having a strategy focused on the legacy objectives, which this evaluation method provided. It is the 'focus on ensuring numbers are consistently growing' (Respondent 29 - CEO). With others providing more specific detail, 'our KPIs are broken down into specific areas such as HE/FE, local delivery, events, teachers etc. This enables us to focus where our work will be to increase participation' (Respondent 85 - regional manager). This suggests an improvement in organisational processes and ensures the NGBs had direction and focused on the legacy objective.

In addition, many respondents (34\%) noted that the APS and SE evaluations systems led to the development of NGBs individual insight and monitoring teams. One respondent stated that it gave them 'a greater understanding of who plays the sport and in what numbers - a better feel for who our customers are and what they require' (Respondent 32 - CEO). This was reinforced by another individual who stated:

'It has made our research and insight so strong [...] It has strengthened us, because we have had to get that research, so now our data is much better and advanced. We improved as an 
organisation as we were challenged. But we signed up to the APS so I guess we can't complain' (Respondent 91 - national manager).

\subsection{Planning and club engagement}

Improved planning and club engagement was mentioned as a necessary change to ensure legacy production, reinforcing the need for a clear, positive and planned leveraging strategy (Preuss 2015). As NGBs and the volunteer club network need to 'be ready! Staff in place, structures in place' (Respondent 70 - national manager). As one national manager (Respondent 99) stated: '[if you] fail to prepare, prepare to fail'), as '[you must] be prepared for an influx of interest and have the suitable processes in place to deal with this interest across all your networks' (Respondent 11). Stronger, long-term planning and club engagement was noted by $32 \%$ of participants as 'greater engagement with our regional and local clubs and bodies is imperative to ensure sustainable benefits' (Respondent 77 - national manager). Whereas, others, felt in agreement with London 2012, but through their 'ideal' perspective were doubtful on the impact that SMEs can have independently and reinforced the importance of its incorporation into a long-term policy strategy and development plan (Smith 2014b). A national manager (Respondent 76) made the following suggestions: '(1) Research - understand what sustainable development really means (2) Decide what is best for your sport (3) Stick to the plan (4) Only use the Olympics as a 'boost' and not as the centre point of your long plan (5) Do NOT chase the money that may be available (6) Be very realistic in the potential long-term benefits of an Olympic Games'.

Insight was also mentioned as critical to the success and development of some NGBs to align with the monitoring and evaluation process. One CEO states:

'Our community sports strategy is based on strong insight and evidence ...We recognised at an early stage that NGB's needed to become consumer focused ... [and] consider our capacity for growth and ensure that increases in participation could be sustained and managed. The consistency of the community strategy is business critical to our NGB'(Respondent $76-$ CEO).

\subsection{Local participation programmes}

NGB respondents reflected on their practices and what they would change if they had the chance to host again. The importance of local participation programmes was suggested, as you need to 'consult with communities, find out what would make a difference on the ground, plan specific campaigns and initiatives that have a higher chance of working and use the profile of the games to really push them' (Respondent 93 - regional manager).

This allows the local communities and VSCs to take control and feel involved in the legacy production, which was identified by survey respondents as one of the main issues with club engagement and communication due to the clubs' negative feelings towards their opportunities for engagement and involvement. This proposed change for future SMEs hosts would ensure that by encouraging a more local approach through the 'material' layer, this may result in a change in the 'artefactual' interpretation of legacy production, which through its current application has been seen negatively. A CEO states 'the equation is fairly simple: Create local opportunities + volunteers/ staff to drive + local \& national promotion of the opportunities/benefits = increased participation' (Respondent 60). Partnerships within the local communities were also mentioned as essential to gain an insight into the demographics of the area to enable realistic legacy production.

One participant states 'keep it local. Work local patches with vigour. Gain support of local 680 agencies. Sport England is ... usually paraded under the banner of "metrics" or "insight" which leave little imprint on the sporting landscape' (Respondent 99 - national manager). This illustrates a clear recommendation for future SMEs hosts, that when developing leveraging strategies to achieve a participation legacy, utilise the local communities and provide them with the opportunities and resources to drive the national objective. Their structures, awareness and knowledge of 
that community are already in place and this may improve the VSCs consensus with the legacy policy, if they have involvement and ownership in the strategy.

\section{Conclusion}

It is essential to understand how a SME was leveraged, through the viewpoints and attitudes of NGB senior staff. The use of $C R$ allowed the different layers of reality to be investigated and discussed adding to the understanding and explanation of leveraging and legacy conceptualisation. This research provided empirical findings to aid the initial investigation into NGB stakeholder's opinions and their perceptions, which are critical in shaping and guiding the legacy creation and policy implementation process. Valuable findings emerged relating to club engagement, communication issues, competition felt between NGBs and VSCs, NGB capacity and evaluation methods. These illustrate the multidimensional constructs that formulate policy implementation and provide an account of NGBs role and attitudes in the legacy process.

Additionally, recommendations can be suggested, which will be useful to future SMEs hosts and national sports organisation such as NGBs and national sports federations. Recommendations also AQ13 include utilising local participation programmes and engaging the local communities and VSCs to improve the implementation process. Furthermore, upskilling volunteers and coaches to ensure they understand the requirements of the leveraging strategy is critical. It would be beneficial to create a VSC database to provide an insight into the individual VSCS characteristics and priorities. These recommendations can aid future leveraging strategies for national sporting organisations prior to hosting SMEs and policy implementation.

This study is one of the first to investigate the attitudes of key stakeholders (NGBs) within the legacy creation process, increasing the understanding of the influence and impact that their views can have within the sports development sector. Further insights in the perceptions of these key stakeholders, across a wider portfolio of sports events would allow a clearer literature base to emerge, depicting the key role these stakeholders play. In the context of this study, a multilayered survey has been developed for this exploratory research and provides a valuable tool from which future studies can adapt and improve in order to investigate sports organisations and other key stakeholders' involvement with future SMEs within AQ14 their cultural contexts.

\section{Notes}

1. The Active People Survey is the largest sport and active recreation survey. It is a telephone survey for adults, 14 years old and above who live in England. It identifies participation trends based on specific categories such as location, participation duration and other demographic characteristics (Sport England 2016b).

2. About 5 of these 46 sports were unable to participate due to multiple reasons such as staff capacity, existing research commitments, time constraints and the number of research requests received.

3. Clubmark is an accreditation scheme for community sports clubs and demonstrates high standards of welfare, equity, coaching and management within those clubs (Sport England 2016c).

4. The IQR represents the 25 th percentile and the 75th percentile for each scale item.

5. The three variables with the * were transformed at the point of analysis through SPSS, from the negative wording to more positive wording, ensuring consistency between all scale items.

\section{Disclosure statement}

No potential conflict of interest was reported by the authors.

\section{References}

AQ15 Bardach, E., 1977. The implementation game: what happens after a bill becomes a law. Vol. 1, Cambridge, MA: MIT Press. Bayle, E. and Robinson, L., 2007. A framework for understanding the performance of national governing bodies of sport. European sport management quarterly, 7 (3), 249-268. doi:10.1080/16184740701511037

AQ16 Bloyce, D. and Smith, A., 2009. Sport policy and development: an introduction. Routledge. 
Bryman, A., 2008. Social research methods. Oxford: OUP.

Byers, T., 2013. Using critical realism: a new perspective on control of volunteers in sport clubs. European sport management quarterly, 13 (1), 5-31. doi:10.1080/16184742.2012.744765

Cashman, R., 1998. Olympic legacy in an Olympic city: monuments, museums and memory. Paper presented at the Fourth International Symposium for Olympic Research; Global and Cultural Critique: problematizing the Olympic Games. 107-114.

Cashman, R., 2003. In M. de Moragas, C. Kennett, and N. Puig, eds. What is Olympic legacy" in the legacy of the Olympic games, 1984-2002. Lausanne: International Olympic Committee, 31-42.

$\mathrm{AQ18}$

Chalip, L., 2004. Beyond impact: a general model for sport event leverage. In: B.W. Ritchie and D. Adair, eds. Sport tourism: interrelationships, impacts and issues. Clevedon: Channel View Publications, 226-252.

Chalip, L., 2006. Towards social leverage of sport events. Journal of sport \& tourism, 11 (2), 109-127. doi:10.1080/ 14775080601155126

Chalip, L., 2014. From legacy to leverage. In: J. Grix, ed. Leveraging legacies from sports mega events: concepts and cases. New York, NY: Palgrave MacMillan, 1-12.

Chappelet, J.L., 2008. Olympic environmental concerns as a legacy of the winter games. The international journal of the history of sport, 25 (14), 1884-1902. doi:10.1080/09523360802438991

Charlton, T., 2010. 'Grow and Sustain': the role of community sports provision in promoting a participation legacy for the 2012 Olympic games. International journal of sport policy and politics, 2 (3), 347-366. doi:10.1080/ 19406940.2010 .519340

Corbin, J.M. and Strauss, A., 1990. Grounded theory research: procedures, canons, and evaluativecriteria. Qualitative sociology, 13, 3-21. doi:10.1007/BF00988593

Cornelissen, S. and Swart, K., 2006. The 2010 football World cup as a political construct: the challenge of making good on an African promise. The sociological review, 54 (2), 108-123. doi:10.1111/j.1467-954X.2006.00656.x

Cuskelly, G., et al., 2006. Volunteer management practices and volunteer retention: a human resource management approach. Sport management review, 9 (2), 141-163. doi:10.1016/S1441-3523(06)70023-7

Eagleman, A.N., 2013. Acceptance, motivations, and usage of social media as a marketing communications too amongst employees of sport national governing bodies. Sport management review, 16 (4), 488-497. doi:10.1016/j. smr.2013.03.004

Elmore, R.F., 1979. Backward mapping: implementation research and policy decisions. Political science quarterly, 94 (4), 601-616. doi:10.2307/2149628

AQ19 Fasting, K., 2000. Women's Role in National and International Sports Governing Bodies. Women in sport, 441-450.

Fleetwood, S., 2013. Critical realism and systematic dialectics: a reply to Andrew Brown. Work, employment \& society, 0950017013501955.

Fleetwood, S. and Ackroyd, S., 2004. Critical realist applications in organisation and management studies. Vol. 11. Psychology Press.

Frawley, S. and Cush, A., 2011. Major sport events and participation legacy: the case of the 2003 Rugby World Cup. Managing leisure, 16 (1), 65-76. doi:10.1080/13606719.2011.532605

Frawley, S., Toohey, K., and Veal, A.J., 2013. Managing sport participation legacy at the Olympic games. UK: Palgrave Macmillan, 66-83.

Garrett, R., 2004. The response of voluntary sports clubs to Sport England's lottery funding: cases of compliance, change and resistance. Managing leisure, 9 (1), 13-29. doi:10.1080/1360671042000182973

Girginov, V. (2014) Social legacy of the Olympic games. HEA Hospitality, Leisure, Sport and Tourism (HLST) subject centre for the UK at Oxford Brookes University [Online]. Available from: brookes.ac.uk [Accessed 5 Apr 2016].

Goggin, M.L., et al., 1990. Implementation theory and practice. Toward a third generation. New York: Harper Collins.

Gratton, C., Dobson, N., and Shibli, S., 2000. The economic importance of major sports events: a case-study of six events. Managing Veisure, 5 (1), 17-28. doi:10.1080/136067100375713

AQ23 Gratton, C. and Jones, I., 2004. Analyzing data II: Qualitative data analysis, Research methods for sport studies.

Griffiths, M. and Armour, K., 2013. Physical education and youth sport in England: conceptual and practical foundations for an Olympic legacy? International journal of sport policy and politics, 5 (2), 213-227. doi:10.1080/ 19406940.2012.656676

AQ24 Grix, J., 2010. The foundations of research. Palgrave Macmillan.

Grix, J., 2012. 'Image'leveraging and sports mega-events: Germany and the 2006 FIFA World Cup. Journal of sport \& tourism, 17 (4), 289-312. doi:10.1080/14775085.2012.760934

Grix, J., 2013. Sport politics and the Olympics. Political studies review, 11 (1), 15-25. doi:10.1111/psr.2013.11.issue- 1

Grix, J. and Brannagan, P.M., 2016. Of mechanisms and myths: conceptualising states' "soft power" strategies through sports mega-events. Diplomacy \& statecraft, 27 (2), 251-272. doi:10.1080/09592296.2016.1169791

Harris, S. and Houlihan, B., 2014. Delivery networks and community sport in England. International journal of public sector management, 27 (2), 113-127. doi:10.1108/IJPSM-07-2013-0095

Harris, S., Mori, K., and Collins, M., 2009. Great expectations: voluntary sports clubs and their role in delivering national policy for English sport. VOLUNTAS: international journal of voluntary and nonprofit organizations, 20 (4), 405-423. doi:10.1007/s11266-009-9095-y 
Hede, A.-M., 2005. Sports-events, tourism and destination marketing strategies: an Australian case study of Athens 2004 and its media telecast. Journal of sport tourism, 10 (3), 187-200. doi:10.1080/14775080500422452

Hindson, A., Gidlow, B., and Peebles, C., 1994. The trickledown effect of top-level sport: myth or reality? A case study of the Olympics. Australian journal of leisure and recreation, 4 (1), 16-24.

Hjern, B., 1982. Implementation research—the link gone missing. Journal of public policy, 2 (03), 301-308. doi:10.1017/ S0143814X00001975

Hjern, B. and Hull, C., 1982. Implementation research as empirical constitutionalism. European journal of political research, 10 (2), 105-115. doi:10.1111/ejpr.1982.10.issue-2

Hjern, B. and Porter, D., 1981. Implementation structures: a new unit of administrative analysis. Organization studies, $2, \quad 800$ 211-227. doi:10.1177/017084068100200301

Hogwood, B.W. and Gunn, L.A., 1984. Policy analysis for the real world. Vol. 69, Oxford: Oxford University Press.

Hums, M.A., Moorman, A.M., and Wolff, E.A., 2003. The inclusion of the paralympics in the Olympic and amateur sports act: legal and policy implications for integration of athletes with disabilities into the United States Olympic committee and national governing bodies. Journal of sport \& social issues, 27 (3), 261-275. doi:10.1177/ 0193732503255480

IOC, 2002. International Olympic committee (2002) conclusions and recommendations: international symposium on legacy of the Olympic games, 1984-2000.

Kellett, P., Hede, A.M., and Chalip, L., 2008. Social policy for sport events: leveraging (relationships with) teams from other nations for community benefit. European sport management quarterly, 8 (2), 101-121. doi:10.1080/ 16184740802024344

Kjellberg, F. and Reitan, M., 1995. Studiet av offentlig politick [The Study of Public Policy]. Oslo: Tano

Knott, B., Allen, D., and Swart, K., 2012. Stakeholder reflections of the tourism and nation-branding legacy of the 2010 FIFA World Cup for South Africa. African journal for physical, health education, recreation and dance, 1, 115-125.

Lipsky, M., 1980. Street-level bureaucracy: dilemmas of the individual in public services. New York: Russell Sage Foundation.

MacAloon, J.J., 2008. 'Legacy'as managerial/magical discourse in contemporary Olympic affairs. The international journal of the history of sport, 25 (14), 2060-2071. doi:10.1080/09523360802439221

Marsh, D., 1999. Post war British politics in perspective. London: Polity Press.

Matland, R.E., 1995. Synthesizing the implementation literature. The ambiguity-conflict model of policy implementation. Journal of public administration research and theory, $5,145-174$.

May, T., Harris, S., and Collins, M., 2013. Implementing community sport policy: understanding the variety of voluntary club types and their attitudes to policy. International journal of sport policy and politics, 5 (3), 397-419. doi:10.1080/ 19406940.2012.735688

McCartney, G., et al., 2010. The health and socioeconomic impacts of major multi-sport events: systematic review (1978-2008). BMJ, 340, c2369. doi:10.1136/bmj.c2369

Nichols, G. and James, M., 2008. One size does not fit all: implications of sports club diversity for their effectiveness as a policy tool and for government support. Managing leisure, 13 (2), 104-114. doi:10.1080/13606710801933461

AQ26 Nicholson, M., Hoye, R., and Houlihan, B., eds., 2010. Participation in sport: international policy perspectives. Routledge.

O'Brien, D., 2006. Event business leveraging the Sydney 2000 Olympic games. Annals of tourism research, 33 (1), 240 261. doi:10.1016/j.annals.2005.10.011

Papadimitriou, D. and Taylor, P., 2000. Organisational effectiveness of Hellenic national sports organisations: a multiple constituency approach. Sport management review, 3 (1), 23-46. doi:10.1016/S1441-3523(00)70078-7

Pappous, A. and Hayday, E.J., 2015. A case study investigating the impact of the London 2012 Olympic and Paralympic Games on participation in two non-traditional English sports, Judo and Fencing. Leisure studies (1-17).

Pressman, J.L. and Wildavsky, A.B., 1973. Implementation: how grert expectations in Washington are dashed in Oakland; or, why it's amazing that federal programs work at all. University of California Press.

Preuss, H., 2004. The economics of staging the Olympics: a comparison of the Games, 1972-2008. Edward Elgar Publishing.

Preuss, H., 2007. The conceptualisation and measurement of mega sport event legacies. Journal of sport \& tourism, 12 (3-4), 207-228. doi:10.1080/14775080701736957

Preuss, H., 2015. A framework for identifying the legacies of a mega sport event. Leisure studies, 34 (6), $643-664$. doi:10.1080/02614367.2014.994552

AQ30 Pülzl, H. and Treib, O., 2006. 7 Implementing public policy. Handbook of public policy analysis, 89.

Reed, M.l., 1997. In praise of duality and dualism: rethinking agency and structure in organizational analysis. 845 Organization studies, 18 (1), 21-42. doi:10.1177/017084069701800103

Sabatier, P. and Mazmanian, D., 1980. The implementation of public policy: a framework of analysis*. Policy studies journal, 8 (4), 538-560. doi:10.1111/psj.1980.8.issue-4

Shaw, S. and Penney, D., 2003. Gender equity policies in national governing bodies: an oxymoron or a vehicle for change? European sport management quarterly, 3 (2), 78-102. doi:10.1080/16184740308721942 
Skille, E.Å., 2008. Understanding sport clubs as sport policy implementers a theoretical framework for the analysis of the implementation of central sport policy through local and voluntary sport organizations. International review for the sociology of sport, 43 (2), 181-200. doi:10.1177/1012690208096035

Smith, A., 2014a. "De-risking" East London: Olympic regeneration planning 2000-2012. European planning studies, 22 (9), 1919-1939. doi:10.1080/09654313.2013.812065

Smith, A., 2014b. Leveraging sport mega-events: new model or convenient justification? Journal of policy research in tourism, leisure and events, 6 (1), 15-30. doi:10.1080/19407963.2013.823976

Sport England, 2016a. '2013-17 whole sport plan investments' [Online] Available from: https://www.sportengland.org/ our-work/national-governing-bodies/sports-we-invest-in/ [Accessed 5 Apr 2016].

Sport England, 2016b. 'Active people survey and active people interactive' [Online] Available from: https://www. sportengland.org/our-work/partnering-local-government/tools-directory/active-people-survey-and-active-peopleinteractive/ [Accessed 5 Apr 2016].

Sport England, 2016c. 'What is club mark?' [Online]. Available from: http://www.sportenglandclubmatters.com/clubmark/ [Accessed 8 Aug 2016].

Taks, M., Chalip, L., and Green, B.C., 2015. Impacts and strategic outcomes from non-mega sport events for local communities. European sport management quarterly, 15 (1), 1-6. doi:10.1080/16184742.2014.995116

Taks, M., et al., 2014. Evaluating sport development outcomes: the case of a medium-sized international sport event. European sport management quarterly, 14 (3), 213-237. doi:10.1080/16184742.2014.882370

Taylor, M. and O'Sullivan, N., 2009. How should national governing bodies of sport be governed in the UK? an exploratory study of board structure. Corporate governance: an international review, 17 (6), 681-693. doi:10.1111/ j.1467-8683.2009.00767.x

Theodoraki, E.I. and Henry, I.P., 1994. Organisational structures and contexts in British national governing bodies of sport. International review for the sociology of sport, 29 (3), 243-265. doi:10.1177/101269029402900302

Tsoukas, H., 1994. What is management? an outline of a metatheory. British journal of management, 5, $289-301$. doi:10.1111/bjom.1994.5.issue-4

Van Meter, D.S. and Van Horn, C.E., 1975. The policy implementation process: a conceptual framework. Administration \& society, 6 (4), 445-488. doi:10.1177/009539977500600404

Veal, A.J., Toohey, K., and Frawley, S., 2012. The sport participation legacy of the Sydney 2000 Olympic games and other international sporting events hosted in Australia. Journal of policy research in tourism, leisure and events, 4 (2), 155-184. doi:10.1080/19407963.2012.662619

Weed, M., 2009. The potential of the demonstration effect to grow and sustain participation in sport. A review paper for sport England.

Weed, M., et al., 2012. Developing a physical activity legacy from the London 2012 Olympic and Paralympic games: a policy-led systematic review. Perspectives in public health, 132 (2), 75-80. doi:10.1177/1757913911435758

Winter, S., 1990. Integrating implementation research. In: D.J. Palumbo and D.J. Calista, eds. Implementation and the policy process. Opening up the black box. New York: Greenwood Press, 19-38.

AQ32 Yin, R.K., 2013. Case study research: design and methods. Sage publications. 